\title{
Thoracotomy compared to laparotomy in the traumatic diaphragmatic hernia. Systematic review and proportional methanalysis ${ }^{1}$
}

\author{
Gracilene Pinheiro Silva', Daniele Cristina Cataneo", Antonio Jose Maria Cataneo"II
}

'Fellow Master degree, Postgraduate Program in Medicine, Botucatu School of Medicine, Universidade Estadual Paulista (UNESP), Botucatu-SP, Brazil. Conception and design of the study, acquisition of data, manuscript preparation.

"Associate Professor, Department of Surgery, Botucatu School of Medicine, UNESP, Botucatu-SP, Brazil. Conception and design of the study, acquisition of data, manuscript writing.

"'Chairman, Head, Department of Surgery, Botucatu School of Medicine, UNESP, Botucatu-SP, Brazil. Conception and design of the study, acquisition of data, manuscript writing.

\section{Abstract}

Purpose: To evaluate the most used approach to treat traumatic diaphragmatic ruptures, and in which one the requirement to assess the second cavity is more frequent.

Methods: Systematic review, observational studies. Outcomes: moment of approach, most commonly via addressed and the requirement to open the other cavity. Bases searched: Lilacs, Pubmed, Embase, Clinicaltrials.gov and Web of Science. Statistical analysis: StatsDirect 3.0.121 software.

Results: Sixty eight studies (2023 participants) were included. Approach in acute phase was performed four times more than in chronic phase. Approach: abdominal 65\% (IC 95\% 63$67 \%$ ), thoracic 23\% (IC 95\% 21-24\%), abdominal in the acute phase $75 \%$ (IC 95\% 71-78\%), and chronic 24\% (IC 95\% 19-29\%), thoracic in the acute phase 12\% (IC 95\% 10-14\%) and chronic 69\% (IC 95\% 63-74\%). Thorax opening in the abdominal approach: $10 \%$ (95\% Cl 8-14\%). Abdomen opening in the thoracic approach: $15 \%$ (95\% Cl 7-24\%).

Conclusions: The most common approach was the abdominal. The approach in the acute phase was more common. In the acute phase the abdominal approach is more frequent than the thoracic approach. In the chronic phase the thoracic approach is more frequent than the abdominal one. The requirement to open the second cavity was similar in both approaches. Key words: Hernia Diaphragmatic, Traumatic. Thoracotomy. Laparotomy. Meta-Analysis. 


\section{- Introduction}

Surgical treatment of traumatic diaphragmatic rupture (TDR) can be performed by both abdominal and thoracic approaches. The decision on the cavity to be addressed will depend on the presence or absence of associated lesions, on the experience of the surgeon, and especially on the time from trauma to diagnosis. The preferred approach in the acute phase of trauma is usually the abdominal one because of the possibility of evaluating the abdominal viscera, which may have been damaged. A percentage of $94-100 \%$ of the trauma that injured the diaphragm has multiple associated abdominal lesions ${ }^{1}$. Despite this, some services still prefer the thoracic approach when they can determine by clinic and imaging methods that there was no abdominal viscera lesion. When surgery is performed in the chronic phase of the trauma, consideration should be given to the possibility of herniation of abdominal contents into the thoracic cavity, with the possibility of adhesions between the viscera. This theoretically would hamper the surgical act if the approach was abdominal, causing many surgeons to opt for the thoracic approach. Other surgeons still prefer the abdominal approach, noting that these adhesions can be undone, even by the abdomen. Considered rare by some authors, TDR affects $5-10 \%$ of all severe thoracic-abdominal traumas, but may go unrecognized. Some authors believe that with the technological evolution of imaging tests, it is possible to perform a greater number of TDR diagnoses ${ }^{2}$, but other authors believe that it is possible to reduce false-negative diagnoses only with video-laparoscopy or video-thoracoscopy ${ }^{3}$. Some authors report that the diagnosis of TDR is still neglected even in the intraoperative laparotomies ${ }^{4,5}$.

When discussing which approach to indicate in a TDR, we find varied opinions. Many services prefer abdominal approach in acute injury, and thoracic approach in chronic injury, but there is no consensus. Some studies show a preference for the thoracic approach, even in acute ruptures, since abdominal injuries are ruled out ${ }^{6}$, while others prefer the abdominal approach even in the chronic injury, and some still show that the approach is dependent on the emergency call staff'. In view of the above, the lack of a consensus for a better approach to TDR and a better postoperative period with lower morbidity and mortality, this systematic review was carried out in an attempt to demonstrate the most used approach to the different situations: thoracic or abdominal approach in the acute, chronic, right and left lesion and in which one the requirement to assess the second cavity is more frequent.

\section{Methods}

The project was evaluated by the Ethics Committee in Human Research from Botucatu School of Medicine (UNESP) and obtained exemption for ethical opinion, since it is a systematic review.

\section{Criteria for considering studies for this review}

Types of studies: observational studies that bring the TDR casuistry and have used both the thoracic approach and the abdominal approach to its treatment.

Participants: patients with acute or chronic TDR.

Intervention: treatment by thoracic approach.

Control: treatment through abdominal approach.

Outcomes evaluated:

1- Most common moment for approach (acute or chronic phase). The acute phase was considered up to 30 days after the trauma.

2- Most used approach for all lesions regardless of phase.

3- Most used approach in the acute phase. 
4- The most used approach in the chronic phase.

5- The most used approach in right and left lesions.

6- The requirement to assess the thoracic cavity when first opened the abdominal and vice versa.

7- Blunt trauma and approach pathway in the acute and chronic.

8- Complications related to the approach accessed.

\section{Search methods to identify the studies}

Electronic databases: Pubmed (1966 to December 2016); Embase (1980 to December 2016); Lilacs (1982 to December 2016); Cochrane (1993 to December 2016); Web of Science (1990 to December 2016).

A comprehensive search strategy was used: (Traumatic Diaphragmatic Hernia or Traumatic Diaphragmatic Hernias) and (Laparotomy or Laparotomies or Minilaparotomy or Minilaparotomies) and (Thoracotomy or Thoracotomies).

\section{Data collection and analysis}

Studies selection: two of the researchers (GPS; DCC) independently examined the titles and abstracts to remove irrelevant articles; retrieving relevant full texts; identifying the location and environment of the studies; details of the intervention; the date and duration of the study; examining the full texts for compliance with the eligibility criteria; if necessary contacting the authors to clarify any questions related to the study and making the final decision on the inclusion of the same. Disagreements were resolved by consensus with the participation of all authors. The reasons for excluding any article were documented.

Data extraction and management: details of the eligible studies were extracted using a data extraction sheet specifically for this review with participants' baseline characteristics, interventions, inclusion of the number of participants, outcome measures, and duration of follow-up. Two reviewers (AJMC; GPS) independently extracted all data regarding the interventions studied and planned to resolve any disagreements by discussion.

Assessment of bias risk in included studies: as it was planned to include observational studies bias risk assessments were not made due to lack of consensus for the application of this evaluation in these studies, but would be considered biased and subject to the effect of confounders.

Quantification of the effect of intervention and synthesis of results: each outcome was analyzed by proportional meta-analysis $^{8}$ using a fixed effect, and the proportion of the prevalence of each of the outcomes was obtained, with corresponding 95\% confidence interval. In the comparisons of the prevalences between two proportions, the confidence intervals were analyzed: if there were overlapping of the intervals there was no difference between the prevalences and no overlap occurring there was a difference between them. The analysis was done with the program StatsDirect, version 3.0.121. The results were summarized using the forest plot in which each horizontal line represents an included study. The estimated effect is represented by a square and the size of the square corresponds to the weight of the study in question. The estimate of the combined effect is represented by a diamond located at the bottom of the graph.

We analyzed separately: approach pathways in the acute lesion; approaches in the chronic lesion; approaches to the right lesion; pathways in the lesion to the left; need for thoracic opening when the approach is abdominal; need for abdominal opening when the approach is thoracic; blunt trauma and approach pathway in the acute and chronic. 


\section{- Results}

\section{Description of studies}

\section{Search results}

The survey conducted in December 2016 recovered 288 studies in Medline, 23 in Embase, 59 in the Web of Science and 35 in Lilacs. After the exclusion of duplicates and analysis of titles and abstracts, 106 articles were selected and obtained in complete copies.
Of these, 68 publications were selected for this review (Figure 1).

\section{Included studies}

The 68 included studies ${ }^{1,4-7,9-71}$ (Table 1), involved 2023 patients, being 1254 men and 292 women. In 18 studies, totaling 477 patients, gender is not mentioned. The patients' age ranged from six months to 88 years, with a mean of 34 years. Twelve studies do not relate to age.

Table 1 - included articles, author, year, country, number of patients and inclusion period.

\begin{tabular}{|c|c|c|c|}
\hline Author(s) & Country & № patients & Inclusion period \\
\hline Adamthwaite $^{9}$ & South Africa & 32 & does not refer \\
\hline Alar et al. ${ }^{10}$ & Turkey & 29 & does not refer \\
\hline Aliev et al. ${ }^{11}$ & Grek & 32 & does not refer \\
\hline Al-Salem ${ }^{12}$ & Saudi Arabia & 7 & 1992 to 2007 \\
\hline Antoini, et al. ${ }^{13}$ & Maroc & 6 & $01 / 2002$ to $09 / 2010$ \\
\hline Arbogast; Gay ${ }^{14}$ & Germany & 34 & 1970 to 1976 \\
\hline Athanassiadi et al. ${ }^{15}$ & Greece & 41 & 1988 to 1997 \\
\hline Basso et al. ${ }^{16}$ & Chile & 3 & does not refer \\
\hline Beauchamp et al. ${ }^{17}$ & Canada & 24 & 1970 to 1981 \\
\hline Beigi et al. ${ }^{5}$ & Iran & 34 & $08 / 2004$ to $06 / 2008$ \\
\hline Brown; Richardson ${ }^{18}$ & USA & 41 & 1957 to 1982 \\
\hline Cerdán-Pascual et al. ${ }^{19}$ & Spain & 7 & 1999 to 2005 \\
\hline Chen; Wilson ${ }^{20}$ & USA & 62 & 1979 to 1989 \\
\hline Clarke et al. ${ }^{4}$ & South Africa & 54 & $09 / 2006$ to $09 / 2007$ \\
\hline Çubukçu et al. ${ }^{21}$ & Turkey & 21 & 1995 to 1998 \\
\hline Fékétéet al. ${ }^{22}$ & France & 13 & does not refer \\
\hline Feliciano et al..$^{23}$ & USA & 16 & 1980 to 1988 \\
\hline Forni et al. ${ }^{24}$ & Italy & 50 & 19 years \\
\hline Freixinet et al. ${ }^{25}$ & Spain & 33 & 1978 to 1985 \\
\hline Ganie et al. ${ }^{26}$ & India & 21 & does not refer \\
\hline Gao et al. ${ }^{27}$ & China & 256 & does not refer \\
\hline Garbuio et al. ${ }^{28}$ & France & 45 & $03 / 1969$ to $09 / 1996$ \\
\hline Grillo et al..$^{29}$ & Saudi Arabia & 10 & 1987 to 1997 \\
\hline Guner et al. ${ }^{30}$ & Turkey & 8 & 2002 to 2010 \\
\hline Gwenly2 ${ }^{7}$ & Egypt & 44 & 1998 to 2007 \\
\hline Haciibrahimoglu et al. ${ }^{31}$ & Turkey & 18 & 1993 to 2000 \\
\hline $\mathrm{Hani}^{32}$ & Jordan & 4 & 2002 to 2006 \\
\hline Hegarty et al. ${ }^{33}$ & South Africa & 25 & does not refer \\
\hline
\end{tabular}




\begin{tabular}{|c|c|c|c|}
\hline Herrera; Vázquez ${ }^{34}$ & México & 7 & does not refer \\
\hline Hibbert et al. ${ }^{35}$ & USA & 6 & $01 / 1975$ to $12 / 1977$ \\
\hline Holmet al. ${ }^{36}$ & England & 42 & 1975 to 1986 \\
\hline Hwanget al. ${ }^{37}$ & Korea & 40 & $01 / 2000$ to $12 / 2007$ \\
\hline Karnak et al. ${ }^{38}$ & Turkey & 15 & 1977 to 1998 \\
\hline Kishore, et al. ${ }^{39}$ & India & 27 & $03 / 2003$ to $03 / 2008$ \\
\hline Lenot et al. ${ }^{40}$ & France & 21 & 1958 to 1986 \\
\hline Lin et al. ${ }^{41}$ & China & 24 & does not refer \\
\hline Lindseyet al. ${ }^{42}$ & Australia & 3 & does not refer \\
\hline Losanoff et al. ${ }^{43}$ & USA & 45 & 1991 to 2002 \\
\hline Matsevych $^{1}$ & South Africa & 12 & 2003 to 2006 \\
\hline Matthews et al. ${ }^{44}$ & USA & 17 & $01 / 1997$ to $01 / 2001$ \\
\hline Mattila et al. ${ }^{45}$ & Finland & 50 & 1954 to 1973 \\
\hline Matz et al. ${ }^{46}$ & Israel & 3 & 1997 to 1998 \\
\hline Mihos et al. ${ }^{47}$ & Greece & 65 & $01 / 1989$ to $05 / 2000$ \\
\hline Montresor et al. ${ }^{48}$ & Italy & 5 & does not refer \\
\hline Nadal et al. ${ }^{49}$ & Brazil & 5 & 1985 to 1990 \\
\hline Noonet et al. ${ }^{50}$ & USA & 22 & 1941 to 1965 \\
\hline Okan et al. ${ }^{51}$ & Turkey & 10 & 2001 to 2009 \\
\hline Okur et al. ${ }^{52}$ & Turkey & 22 & $01 / 2000$ to $12 / 2011$ \\
\hline Olin $^{53}$ & Sweden & 11 & 1960 to 1972 \\
\hline Pantelis et al. ${ }^{54}$ & Germany & 21 & 1993 to 2004 \\
\hline Payne; Yellin 55 & USA & 36 & $01 / 1969$ to $12 / 1980$ \\
\hline Peer et al. ${ }^{6}$ & India & 29 & $01 / 1998$ to $10 / 2008$ \\
\hline Plate; Demischew ${ }^{56}$ & Germany & 10 & 34 years \\
\hline Ruf et al. ${ }^{57}$ & Germany & 99 & 1976 to 1993 \\
\hline Sanli et al. ${ }^{58}$ & Turkey & 13 & does not refer \\
\hline Sharma ${ }^{59}$ & USA & 28 & 1976 to $03 / 1988$ \\
\hline Simpson et al. ${ }^{60}$ & England & 16 & $01 / 1990$ to $08 / 1998$ \\
\hline Sözübir, et al. ${ }^{61}$ & Turkey & 8 & 1988 to 2001 \\
\hline Sukul et al. ${ }^{62}$ & Netherlands & 63 & $01 / 1973$ to $01 / 1990$ \\
\hline Suttonet al. ${ }^{63}$ & USA & 25 & 1933 to 1965 \\
\hline Tan et al. ${ }^{64}$ & Singapore & 14 & $03 / 2002$ to $10 / 2008$ \\
\hline Tarladaçalışır et al. ${ }^{65}$ & Turkey & 30 & $05 / 1997$ to $05 / 2009$ \\
\hline Tiberio et al. ${ }^{66}$ & Italy & 33 & 1988 to 2003 \\
\hline Turhan et al. ${ }^{67}$ & Turkey & 68 & $07 / 1994$ to $09 / 2005$ \\
\hline van Vugt; Schoots ${ }^{68}$ & Netherlands & 28 & does not refer \\
\hline Vatansev et al. ${ }^{69}$ & Turkey & 38 & $05 / 1988$ to $08 / 2001$ \\
\hline Vergnaud et al. ${ }^{70}$ & Colombia & 12 & does not refer \\
\hline Yalçinkaya et al..$^{71}$ & Turkey & 26 & $08 / 1996$ to $10 / 2005$ \\
\hline
\end{tabular}




\section{Excluded studies}

Thirty eight of full-text articles excluded, and the reasons for exclusion are depicted in Figure 1.

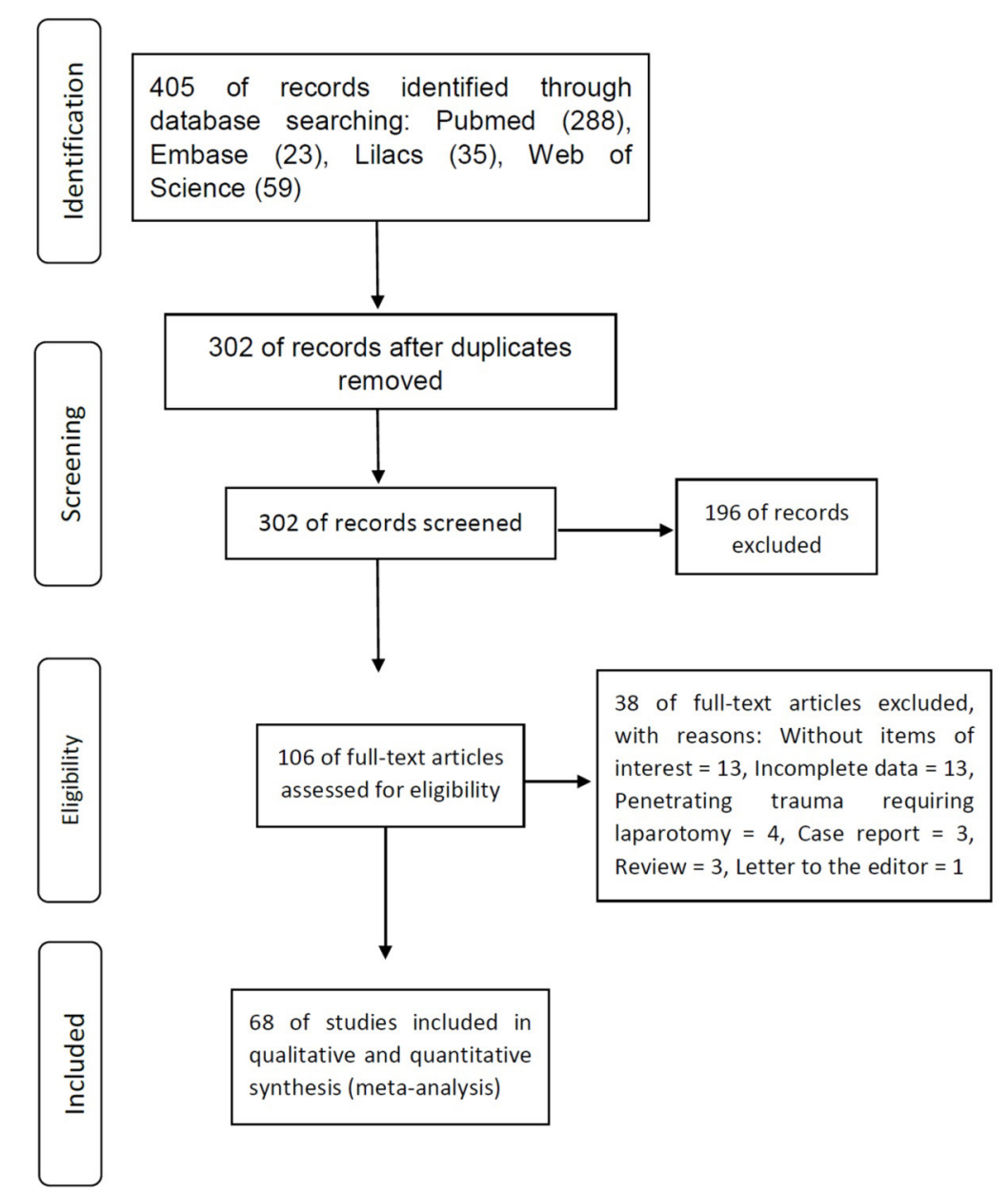

Figure 1 - Flowchart of the selection of the articles included.

\section{Synthesis of results}

Moment of the surgical approach (acute or chronic phase): 1.276 patients were treated in the acute phase and 338 in the chronic phase. They do not report the phase in 409 patients.

Approach: 1273 patients were treated by the abdomen (65\%, 95\% Cl 63-67\%) (Figure $2 \mathrm{~A}), 519$ by thoracic $(23 \%, 95 \% \mathrm{Cl} 21-24 \%)$ (Figure 2B), 219 thoracic and abdominal, eight patients refused approach, three died and one patient was not mentioned the approach. The comparison between abdominal and thoracic accesses is shown in figure $2 \mathrm{C}$ in percentage. 


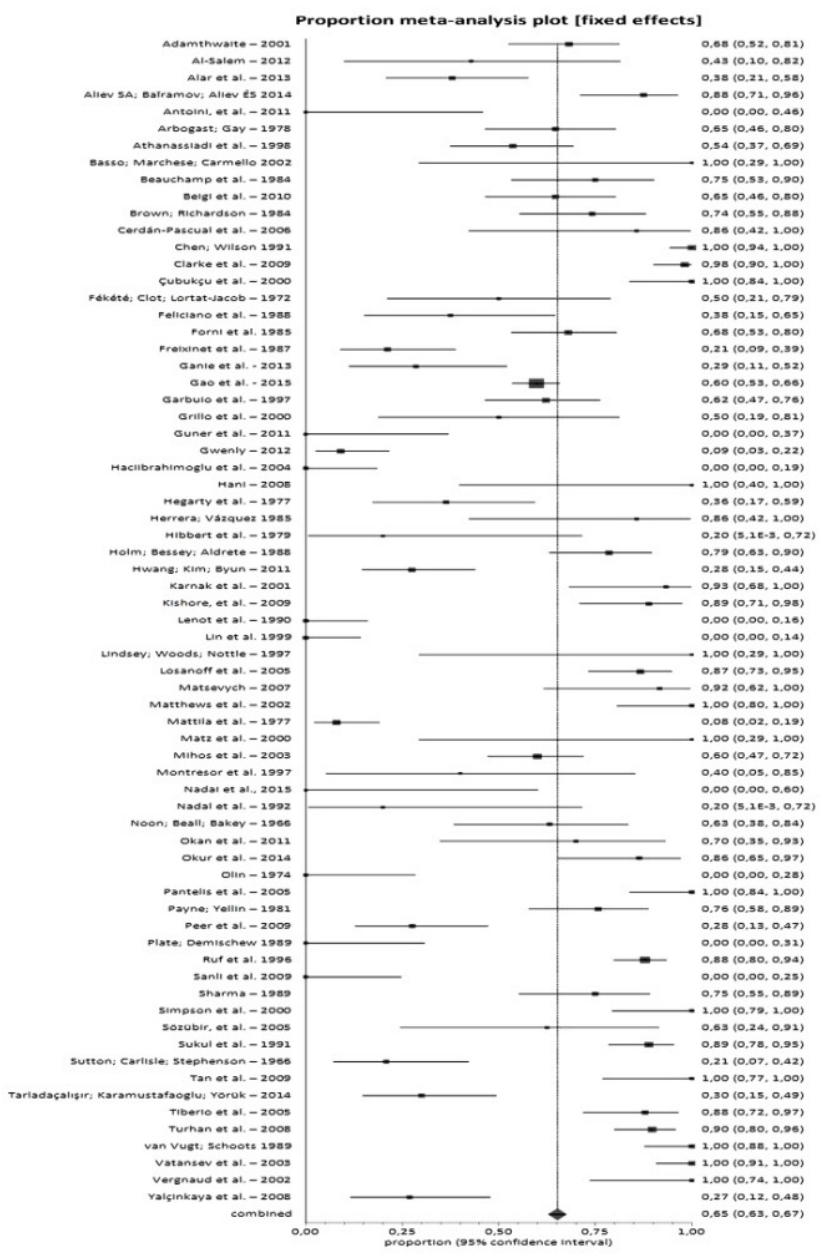

A

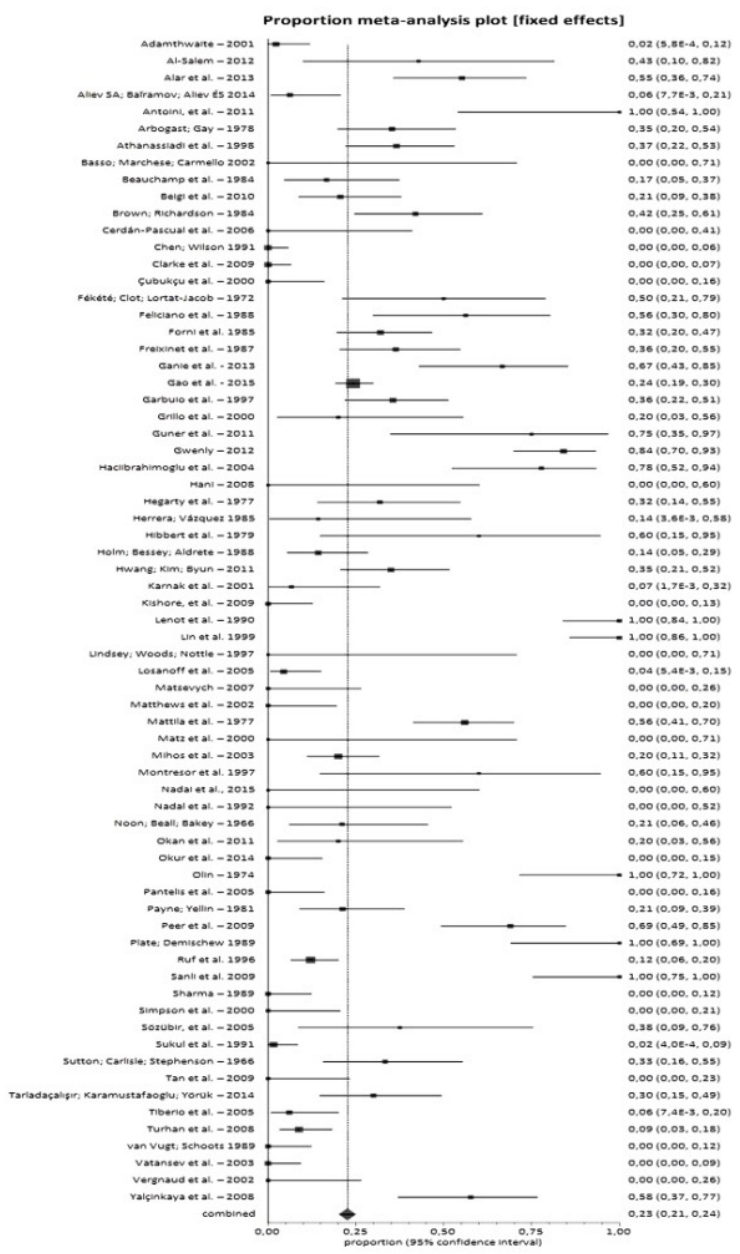

B

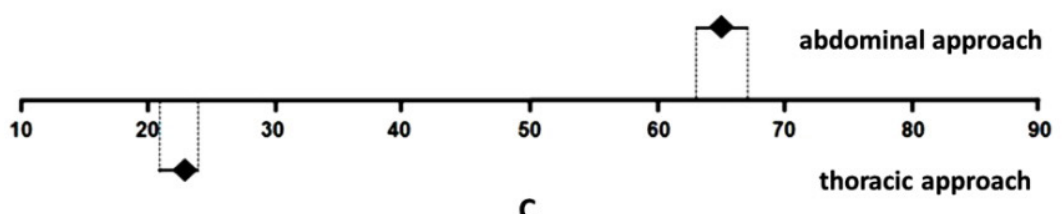

C

Figure 2 - Traumatic diaphragmatic rupture. (A) The abdominal approach occurred in $65 \%$ of the cases, with $95 \% \mathrm{Cl}$ ranging from 63 to $67 \%$. (B) The thoracic approach occurred in $23 \%$ of cases, with $95 \% \mathrm{Cl}$ ranging from 21 to $24 \%$. (C) Comparison between thoracic and abdominal access routes: abdominal intervention is three times more frequent than thoracic.

Approach in the acute phase: thirtytwo studies (1088 patients) do not relate the phase to the approach. Thirty-six studies report 563 abdominal approaches $(75 \%, 95 \%$ $\mathrm{Cl} 71-78 \%)$ (Figure 3A), 138 thoracic (12\%, 95\%
Cl 10-14\%) (Figure 3B), and 89 approaches of the two cavities. The comparison between the abdominal and thoracic approach in the acute lesion is shown in percentage in Figure $3 \mathrm{C}$. 


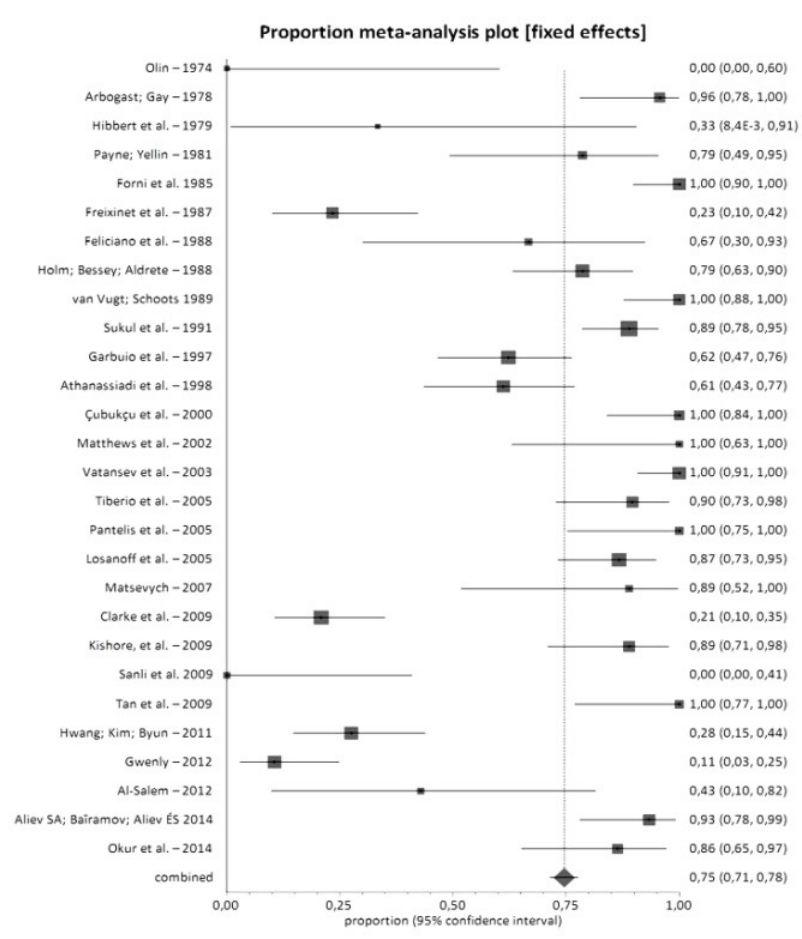

A

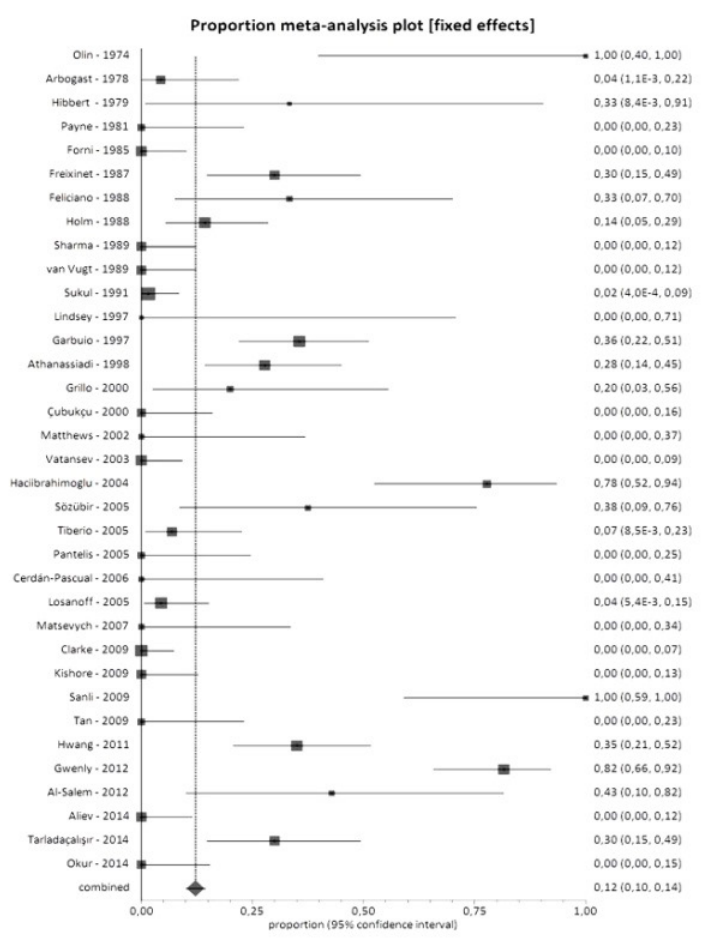

B

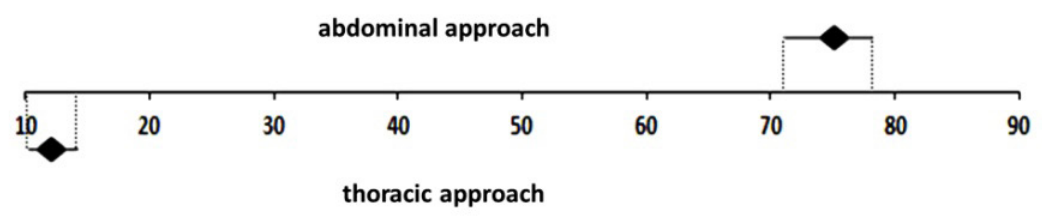

C

Figure 3 - Acute injury. (A) The abdominal approach occurred in $75 \%$ of the cases, with $95 \% \mathrm{Cl}$ ranging from 71 to $78 \%$. (B) The thoracic approach occurred in $12 \%$ of cases, with $95 \% \mathrm{Cl}$ ranging from 10 to $14 \%$. (C) Comparison between abdominal and thoracic approach in acute injury. The abdominal approach is six times more frequent than the thoracic in the acute diaphragmatic lesion.

Approach in the chronic phase: in the chronic phase, 153 approaches were performed on thorax $(69 \%, 95 \% \mathrm{Cl} 63-74 \%)$ (Figure 4A), 76 abdominal $(24 \%, 95 \% \mathrm{Cl}$
19-29\%) (Figure 4B) and 13 approaches in both cavities. The comparison between the abdominal and thoracic approach in chronic lesions in percentage is shown in Figure 4C. 


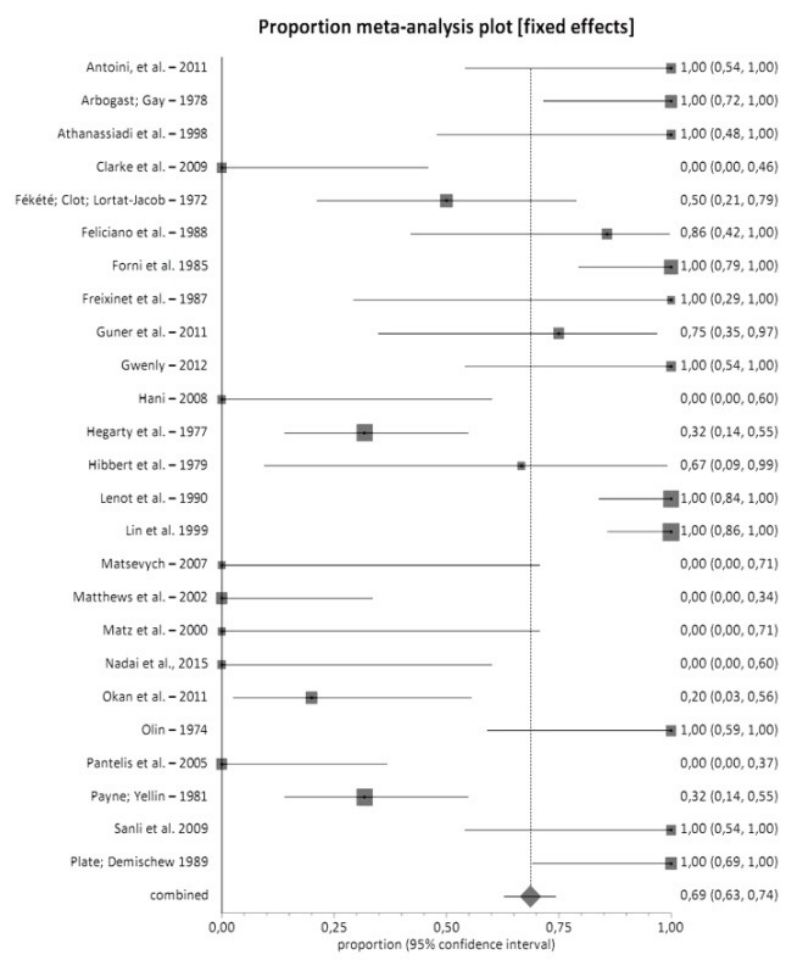

A

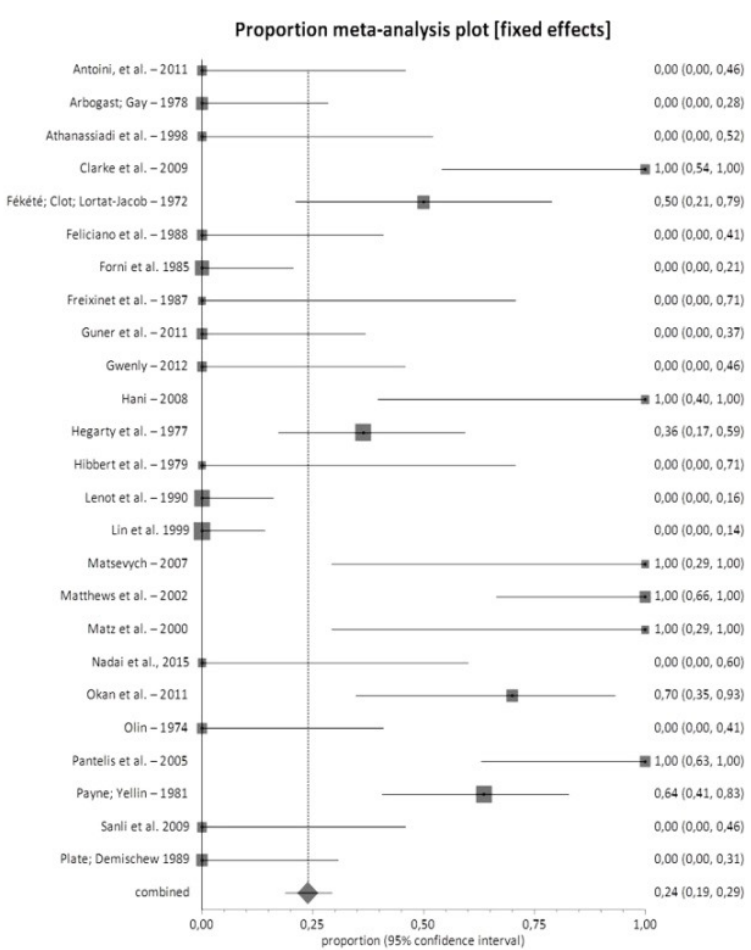

B

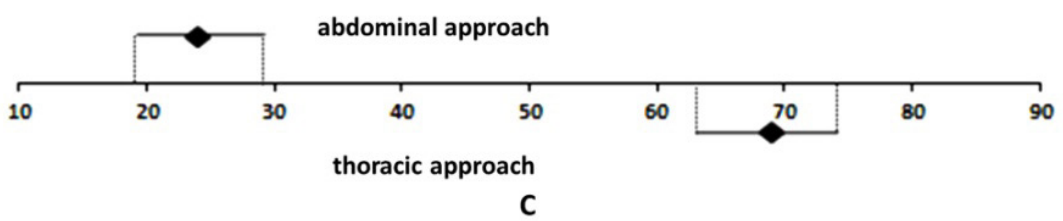

Figure 4 - Chronic injury. (A) The thoracic approach occurred in $69 \%$ of cases, with $95 \% \mathrm{Cl}$ ranging from 63 to $74 \%$. (B) The abdominal approach occurred in $24 \%$ of the cases, with $95 \% \mathrm{Cl}$ ranging from 19 to $29 \%$. (C) Comparison between abdominal and thoracic approach in chronic injury. The thoracic approach is three times more frequent than the abdominal approach in the chronic diaphragmatic lesion.

Abdominal approach with requirement for thoracic assess: only six studies $1,12,27,39,63,66$ reported abdominal onset in a total of 385 patients, with subsequent need for thoracic cavity opening in 39 of them $(10 \% \mathrm{Cl} 95 \%$ 8-14\%) (Figure 5A).
Thoracic approach with requirement for abdominal assess: only three studies ${ }^{11,49,63}$ reported an initial thorax approach in 62 patients, with subsequent need for abdominal cavity assess in 10 of them (15\% Cl 95\% 7-24\%) (Figure 5B). The comparison between the two approaches in relation to requirement for open the other cavity is shown in percentage in Figure $5 \mathrm{C}$. 


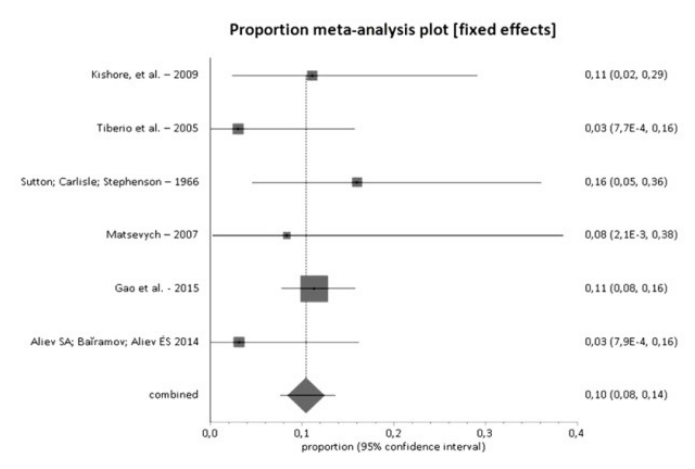

A

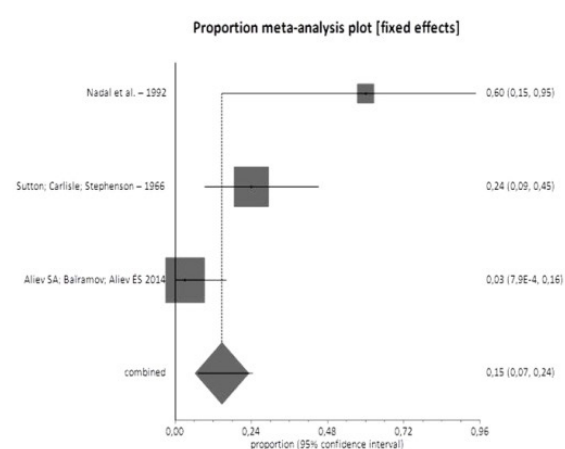

B

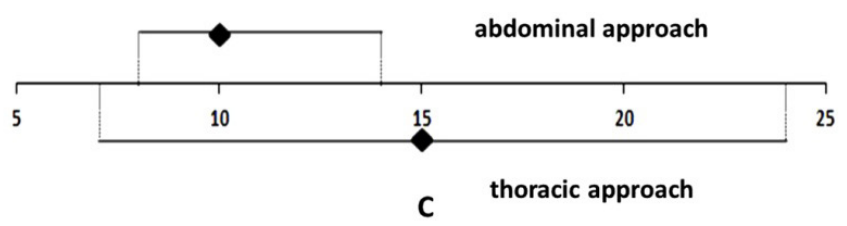

Figure 5 - Opening of the other cavity. (A) In the abdominal approach there was a need for thoracic opening in $10 \%$ of cases, with $95 \% \mathrm{Cl}$ ranging from 8 to $14 \%$. (B) In the thoracic approach, there was a need for abdominal opening in $15 \%$ of the cases, with $95 \% \mathrm{Cl}$ ranging from 7 to $24 \%$. (C) Comparison between the two approach ways in relation to the need to open the other cavity. It was not possible to show difference between the two approaches to the need to open the other cavity due to the wide confidence interval.

Sort of trauma: in 1820 patients it was possible to determine the sort of trauma, 1149 blunt trauma and 671 penetrating trauma. Only 217 patients who suffered blunt trauma were able to correlate the approach with the time of approach (159 in the acute phase and 58 in the chronic phase). Of the 159 patients treated in the acute phase, 63\% (IC 95\% 55-70\%) were abdominal (Figure 6A) and 29\% (IC 95\% 22$36 \%$ ) thoracic (Figure 6B). The comparison between the abdominal or thoracic approach in the acute phase of the blunt trauma is shown in percentage in Figure 6C. Of the 58 blunt traumas treated in the chronic phase, $14 \%$ (IC 95\% 7-24\%) (Figure 7A) were approached abdominally and $82 \%$ (IC 95\% 71\%-90\%), by thoracic approach (Figure 7B). The comparison between the abdominal or thoracic approach in the chronic phase of the blunt trauma is shown in percentage in Figure 7C. 


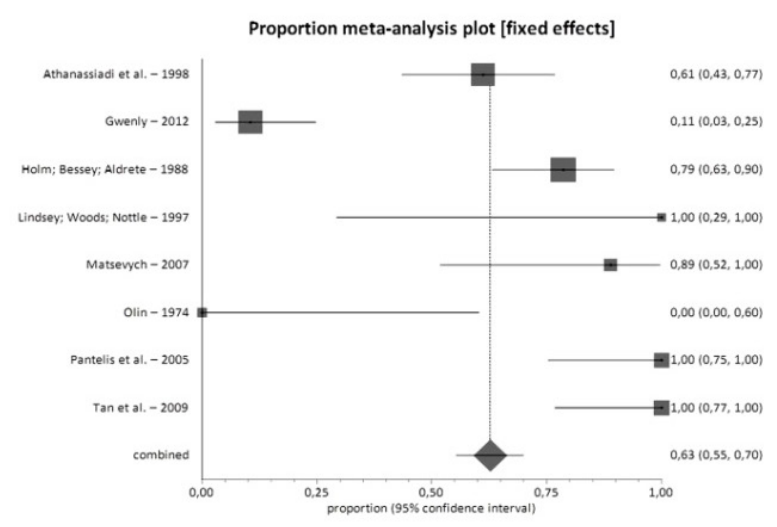

A

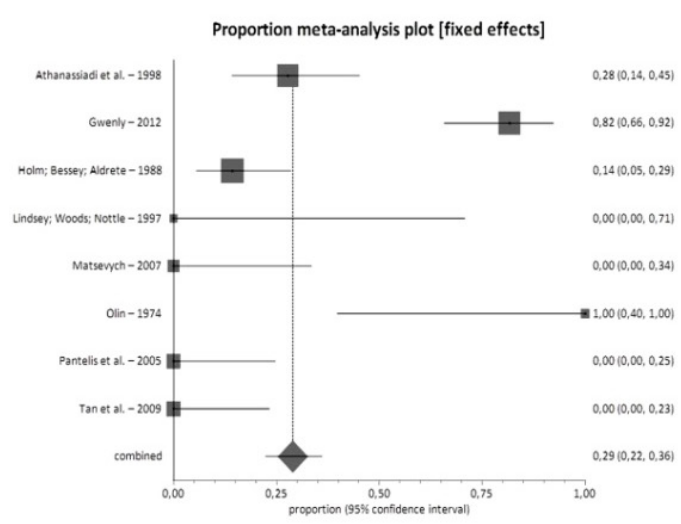

B

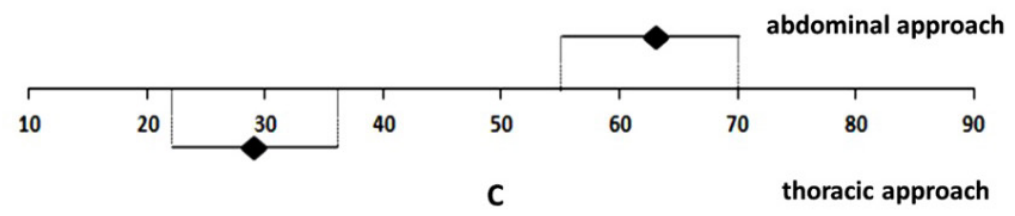

Figure 6-Blunt trauma rupture in the acute phase. (A) The abdominal approach occurred in $63 \%$ of the cases, with $95 \% \mathrm{Cl}$ ranging from 55 to $70 \%$. (B) The thoracic approach occurred in $29 \%$ of cases, with $95 \% \mathrm{Cl}$ ranging from 22 to $36 \%$. (C) Comparison between the abdominal or thoracic approach in the acute phase of blunt trauma. The abdominal approach was chosen twice as much as the thoracic one.

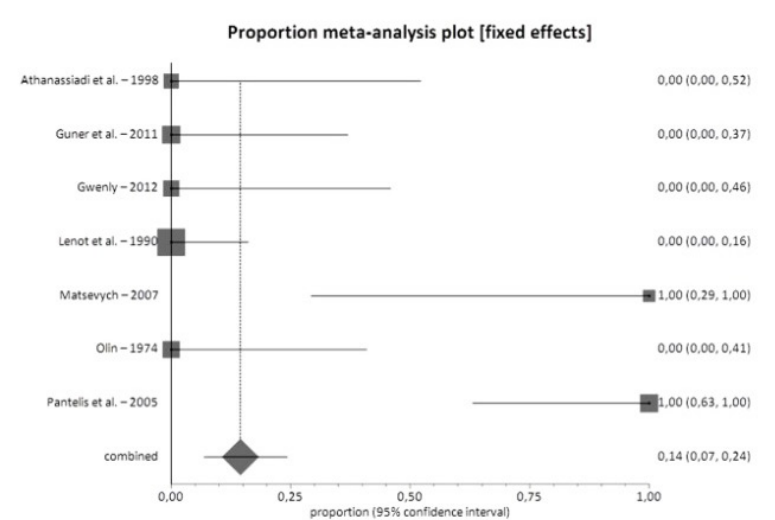

A

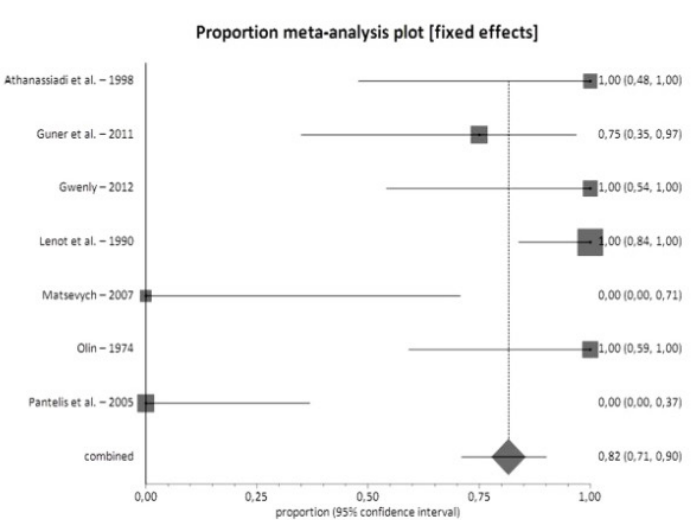

B

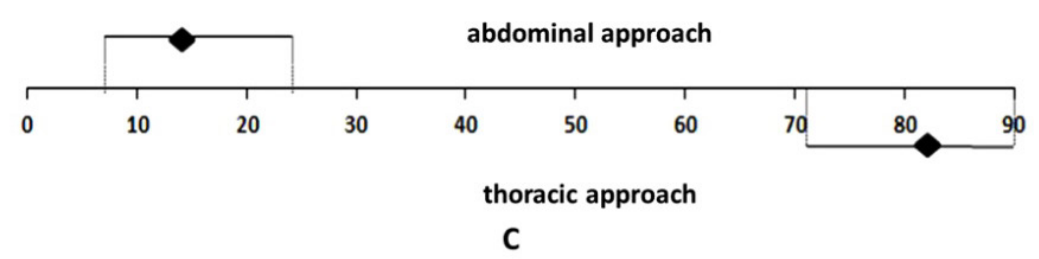

Figure 7 - Rupture by blunt trauma in the chronic phase. (A) Abdominal approach occurred in 14\% of cases, with $95 \% \mathrm{Cl}$ ranging from $7 \%$ to $24 \%$. (B) The thoracic approach occurred in $82 \%$ of the cases, with $95 \% \mathrm{Cl}$ ranging from 71 to $90 \%$. (C) Comparison between the abdominal or thoracic approach in the chronic phase of blunt trauma. The thoracic approach was chosen six times more than the abdominal approach. 
Hemidiaphragm affected: it was possible to collect this data in 54 articles (1359 patients, 1029 on the left, 305 on the right, 25 with bilateral lesion).

Access approach according to the affected side: in the lesions on the right side 11 studies reported the pathway used. The thoracic approach was chosen in 34\% (95\% $\mathrm{Cl} 23-46 \%)$ and abdominal in $60 \%(95 \% \mathrm{Cl} 47-$ $71 \%)$. Sixteen studies reported the approach in lesions on the left side. The thoracic approach occurred in 22\% (IC95\% 17-29\%) and abdominal in 75\% (IC 95\% 68-88\%). The abdominal approach was chosen three to four times more than thoracic.

Diaphragmatic rupture size: four studies report the mean diameter of diaphragmatic lesions $(13 \mathrm{~cm})$. Sixteen studies reported variation from $0.5 \mathrm{~cm}$ to $26 \mathrm{~cm}$.

Type of diaphragmatic repair: in 905 patients it was possible to know the type of diaphragmatic repair, with primary repair in 870 patients and the screen implant in 35.

Herniated organs: the studies address the diaphragmatic lesion describing the possible presence of the hernia and, among the organs that migrate to the thoracic cavity, are mentioned: stomach (414), colon (279), spleen (168), omentum (149), liver (103), small intestine (102), vesicles (4), and kidney (3).

Postoperative complications: the postoperative complications evidenced in the studies were not separated according to the approach. They were: pneumonia (82), atelectasis (38), urinary tract infection (31), surgical wound infection (31), empyema (29), adynamic ileus (22), sepsis (22), diaphragmatic paralysis, renal failure (15), abdominal abscess (10), dehiscence (9), pulmonary thromboembolism (9), among others less common. In 29 articles there were no postoperative complications.

Mortality: there were 128 deaths, with hypovolemic shock being the most frequent cause of mortality, with 58 cases, followed by associated lesions (30), sepsis (25), traumatic brain injury (15), multiple organ failure (11), respiratory distress in the adult (8), respiratory failure (5), pulmonary thromboembolism (3), intraoperative with no cause reported (3), high volume hernia, evolving to cardiorespiratory arrest (2).

Length of hospital stay: twenty-two studies report hospitalization time, but do not separate according to the approach, with 12 presenting the results ranging from a mean of seven to 29 days, and 10 presenting the range of days varying from one to 255 days. One study $^{29}$ reported longer hospitalization time in patients submitted to the two-cavity approach. Length of stay in the Intensive Care Unit was shown in four studies with an average of 10 days.

\section{Discussion}

Analysis of the main results: sixty-eight observational studies were included in this review, with a total of 2023 participants. In these series of cases it was possible to show that the majority of patients who suffered this type of trauma belong to the male gender, with a mean age of 34 years. The predominant trauma mechanism was the blunt, and the left side was the most affected. Most patients were treated in the acute phase. The most commonly used pathway in acute lesions was the abdominal pathway, and in the chronic lesions the most common pathway was the thoracic one. The abdominal approach was three times more common than the thoracic, regardless of the phase. In the acute phase the abdominal approach was performed six times more than the thoracic approach. In the chronic phase the thoracic approach was performed three times more than the abdominal approach. Few 
of the included studies reported the need to open the second cavity, so when opting for the thoracic approach, the need for abdominal cavity opening appears to have been greater than when the option was for the abdominal approach, but due to the small number of cases where it was possible to collect these data, the confidence interval was very wide, making this difference not significant. Perhaps if more studies had shown this data we could have found significant difference. In the acute blunt trauma the abdominal approach was chosen twice as much as the thoracic, but in the chronic phase the thoracic approach was chosen six times more than the abdominal one. The studies report the main postoperative complications (pneumonia, atelectasis, urinary tract infection, surgical wound infection, empyema, adynamic ilium, sepsis, diaphragmatic paralysis), but do not mention in which of these approaches these complications were more frequent. The hospitalization time is quoted in several articles, but it was not possible to relate the access approach with the length of hospital stay. It was also not possible to relate mortality to the approach site. Most of the included studies analyzed the outcomes of interest, but without adequate separation of the acute and chronic phases related to the access approach or the need to open the other cavity, thus reducing the number of participants in various outcomes. No study included quality of life postoperatively or length of hospital stay related to the approach. Some studies showed the time of hospitalization, but none related to the type of surgical approach, and it was not possible to compare in which approach would be longer hospitalization time.

Quality of evidence: included studies were considered as having a high risk of bias because they were retrospective observational studies, thus lowering the quality of evidence. In surgical intervention, due to the difficulty in conducting randomized clinical trials, the quality of evidence is usually poor. In this study of TDR, since most of the cases are operated on urgently, it is much more difficult to randomize the cases to the opening approach, mainly due to different levels of ability on the part of the surgeons on duty. Thoracic surgeons prefer the thoracic approach and abdominal surgeons prefer the abdominal approach, so many studies report that the approach was conditional on the specialty of the surgeon on duty.

Potential biases of this review: studies to approach the diaphragmatic lesion involve different schools and also the qualification of the surgeon, which makes it difficult to combine the results. One example is that in studies in which access to the thoracic surgeon was easy; there was a tendency to the thoracic approach, even in acute lesions. In the acute phase the abdominal approach was more encouraged due to the associated abdominal lesions and the absence of adhesions with thoracic organs. Another potential bias is related to the impact of the trauma, because it was not possible to perform analysis of subgroups of great and small impact. As most diaphragmatic lesions occur due to large impacts, the existence of associated lesions is common, which increases the length of hospital stay, postoperative complications and patients' morbidity and mortality.

Agreements and disagreements with other studies or reviews: this systematic review confirmed some of the findings that isolated studies have shown: the diagnosis is made more in the acute phase; the approach in the acute phase is more frequent through the abdominal approach, and in the chronic phase through thoracic approach. Blunt trauma is more common than the penetrating trauma. The left compromise is significantly greater, both in relation to the right lesion and bilateral 
lesion. As disagreements we have seen that most of the studies show preference for the abdominal approach, even in late diagnoses. Others opt for the thoracic approach even in acute injuries, provided that abdominal injuries are previously ruled out.

What was noticed in the most recent articles of this review was the increase of laparoscopic approaches even in patients with chronic diagnosis. The studies show a better postoperative period, with shorter hospital stay and fewer postoperative complications ${ }^{32,44,46,70}$.

\section{Implications for practice}

There is evidence that in the acute TDR the most used surgical approach is the abdominal, and in the chronic TDR the thoracic, but there are articles that show the opposite. It seems that the greatest benefit for these patients would be their care by a multi professional team composed of thoracic and abdominal surgeons, so that the choice of approach would not be conditioned simply by the surgeon's greater ability to manipulate one or the other of the cavities. Another observation detected in the most current articles is that video thoracoscopy and video laparoscopy could contribute to the diagnosis and treatment of these lesions, with possibilities for a better postoperative period, but this would be a theme for another review.

\section{Implications for research}

Systematic reviews of surgical interventions are difficult to perform, since randomized trials in the surgical area are rare, and in emergency surgeries, rarer still. Therefore, the phrase found in most systematic reviews "there is a need for more randomized, high-quality studies on the subject" would be pointless. What we think could help in future revisions would be the separation of the two approaches, citing the complications, difficulties and facilities related to the approach.

\section{Conclusions}

The approach to TDR in the acute phase is more common than in the chronic phase. In the acute phase the abdominal approach is performed more often than the thoracic approach. In the chronic phase the thoracic approach is performed more frequently than the abdominal approach.

The requirement to assess the thoracic cavity when the first opened was the abdominal cavity was similar to the requirement to open the abdominal cavity when the first opened was thoracic cavity, but few articles provide this information.

In diaphragmatic lesions, both left and right, the abdominal approach is more frequent than the thoracic, but this evidence in the left TDR is much clearer, where the abdominal approach was chosen in almost $80 \%$ of the time.

In the blunt trauma in the acute phase the choice of abdominal pathway was slightly higher than the choice of the thoracic, but in the chronic phase the choice of thoracic approach was much greater than that of the abdominal pathway. It was not possible to demonstrate which approach leads to the greatest number of complications.

\section{References}

1. Matsevych OY. Blunt diaphragmatic rupture: four years' experience. Hernia. 2008;12(1):73-8. doi: 10.1007/s10029-0070283-7.

2. Rafael AA, Rodrigues $P$, Do Carmo $L$, Nascimento C, Machado J, Fonseca JR. Hérnia diafragmática traumática tardia complicada de perfuração intratorácica e quisto hemorrágico gástrico. Acta Méd Port. 2005;18:295-301. 
3. Saad R. Videotoracoscopia no trauma de tórax. In: Clinica Cirúrgica. Cataneo \& Kobayasi. Rio de Janeiro: Editora Revinter; 2003. p.123-7.

4. Clarke DL, Greatorex B, Oosthuizen GV, Muckart DJ. The spectrum of diaphragmatic injury in a busy metropolitan surgical service. Injury. 2009;40(9):932-7. doi: 10.1016/j. injury.2008.10.042.

5. Beigi AA, Masoudpour $H$, Sehhat S, Khademi EF. Prognostic factors and outcome of traumatic diaphragmatic rupture. Ulus Travma Acil Cerrahi Derg. 2010;16(3):215-9. PMID: 20517745.

6. Peer SM, Devaraddeppa PM, Buggi S. Traumatic diaphragmatic hernia-our experience. Int J Surg. 2009;7(6):547-9. doi: 10.1016/j.ijsu.2009.09.003.

7. Gwely NN. Outcome of blunt diaphragmatic rupture. Analysis of 44 cases. Asian Cardiovasc Thorac Ann. 2010;18(3):240-3. doi: $10.1177 / 0218492310368740$.

8. El Dib R, Nascimento Jr P, Kapoor A. An alternative approach to deal with the absence of clinical trials: a proportional meta-analysis of case series studies. Acta Cir Bras. 2013;28(12):870-6. doi: 10.1590/ S0102-86502013001200010.

9. Adamthwaite DN. Penetrating injuries of the diaphragm. Injury. 2001;14(2):151-8. PMID: 3167540.

10.Alar T, Dedeoglu E, Bulut T, Yapucu UM, Dedeoglu B. Acute and delayed traumatic diaphragmatic ruptures presenting at the emergency service: what are we missing? Hong Kong J Emerg Med. 2013;20(3):172-7.

11.Aliev SA, Bairramov Nlu, Aliev ÉS. Features of diagnostics and surgical strategy of diaphragmatic rupture in patients with closed chest and abdominal polytrauma. Vestn Khir Im I I Grek. 2014;173(4):66-72. PMID: 25552110.

12.Al-Salem AH. Traumatic diaphragmatic hernia in children. Pediatr Surg Int. 2012;28(7):687-91. doi: 10.1007/s00383012-3107-5.

13.Atoini $F$, Traibi A, Elkaoui $H$, Elouieriachi F, Elhammoumi M, Sair K, Kabire EH. Missed right post-traumatic diaphragmatic injuries: A review of six cases. Rev Pneumol Clin. 2012;68(3):185-93. doi: 10.1016/j. pneumo.2011.07.005.
14.Arbogast R, Gay B. Ruptures traumatiques du diaphragme. Acta Chir Belg. 1978;77(4):21725.

15. AthanassiadiK, Kalavrouziotis G, Athanassiou $M$, Vernikos $P$, Skrekas $G$, Poultsidi $A$, Bellenis I. Blunt diaphragmatic rupture. Eur J Cardiothorac Surg. 1999;15(4):469-74.

16. Basso MR, Marchese LT, Carmello VT. Hernia diafragmática traumática en niños: manifestación precoz y tardía. Rev Cir Infant. 2002;12(3):176-80.

17. Beauchamp G, Khalfallah A, Girard R, Dube S Laurendeau F, Legros G. Blunt diaphragmatic rupture. Am J Surg. 1984;148(2):292-5.

18.Brown GL, Richardson JD. Traumatic diaphragmatic hernia: a continuing challenge. Ann Thorac Surg. 1985;39(2):1703. PMID: 3970611.

19.Cerdán-Pascual R, Cantín-Blázquez S, Bernal-Jaulín J, Barranco-Domínguez JI, Ruiz-Montoya J, Esarte-Muniain JM. Rotura traumática del diafragma. Revisión de siete casos. Cir Ciruj. 2006;74:425-9.

20.Chen JC, Wilson SE. Diaphragmatic injuries - recognition and management in 62 patients. Am Surg. 1991;57(12):810-5. PMID: 1746800.

21.Cubukçu A, Paksoy M, Gönüllü NN, Sirin $F$, Dülger $M$. Traumatic rupture of the diaphragm. Int J Clin Pract. 2000;54(1):1921. PMID: 10750253.

22.Fékété F, Clot JL, Lortat J. Ruptures du diaphragme. Plaidoyer pour une voie dábord abdominale. A propos de 13 ruptures traumatiques anciennes. Ann Chir. 1973;27:935-41.

23. Feliciano DV, Cruse PA, Mattox KL, Bitondo CG, Burch JM, Noon GP, Beall AC Jr. Delayed diagnosis of injuries to the diaphragm after penetrating wounds. J Trauma. 1988;28(8):1135-44. PMID: 3411640.

24.Forni E, Spelzini P, Rossi G, Clerico D, Lo Monaco G, Bordoni P. Diaphragmatic hernias due to blunt thoracoabdominal trauma. Ital J Surg Sci. 1985;15(2):149-54. PMID: 4044210.

25.Freixinet JL, Segur JM, Mestres CA, Mateu M, Gimferrer JM, Catalán M, Callejas MA, Letang $E$, Sánchez-Lloret J. Traumatic injuries of the diaphragm. Experience in 33 cases. Thorac Cardiovasc Surg. 1987;35(4):215-8. doi: 10.1055/s-2007-1020233. 
26.Ganie FA, Lone GN, Choudhary M, Line H. The characteristics and surgical approach in post-traumatic diaphragmatic hernia: a single center experience. Bull Emerg Trauma. 2013;1(3):108-11. PMID: 4779170.

27.Gao JM, Du DY, Li H, Liu CP, Liang SY, Xiao Q, Zhao SH, Yang J, Lin X . Traumatic diaphragmatic rupture with combined thoracoabdominal injuries: Difference between penetrating and blunt injuries. Chin J Traumatol. 2015;18(1):21-6. PMID: 26169090.

28.Garbuio P, Doury L, Gagneux E, Vichard $\mathrm{PH}$. Réflexions sur les ruptures récentes du diaphragme. À propôs de 45 cas. Chirurgie. 1997;122:338-42.

29.Grillo IA, Jastaniah SA, Bayoumi AH, Karami F, Al-Naami MY, Tarek S, al-Ghamdi B, Eltahir MI, al-Shehri MY. Traumatic diaphragmatic hernia: an Asir Region (Saudi Arabia) experience. Indian J Chest Dis Allied Sci. 2000;42(1):9-14. PMID: 10851816.

30.Guner A, Ozkan OF, Bekar Y, Kece C, Kaya U, Reis E. Management of delayed presentation of a right-side traumatic diaphragmatic rupture. World J Surg. 2012;36(2):260-5. doi: 10.1007/s00268-011-1362-6.

31. Haciibrahimoglu G, Solak O, Olcmen A, Bedirhan MA, Solmazer N, Gurses A. Management of traumatic diaphragmatic rupture. Surg Today. 2004;34(2):111-4. doi: 10.1007/s00595-003-2662-8.

32. Hani MB. A combined laparoscopic and endoscopic approach to acute gastric volvulus associated with traumatic diaphragmatic hernia. Surg Laparosc Endosc Percutan Tech. 2008;18(2):151-4. doi: 10.1097/SLE.0b013e3181659221.

33. Hegarty MM, Bryer JV, Angorn IB, Baker LW. Delayed presentation of traumatic diaphragmatic hernia. Ann Surg. 1978;188(2):229-33. PMID: 1396746.

34. Herrera, C B; Vázquez, R F. Hernia traumática del diafragma en niños. Bol Med Hosp Infant Méx. 1985;42(6):384-8.

35. Hibbert J, Elechi EN, Warner O, Calhoun T, Kurtz LH. Traumatic diaphragmatic hernias. Analysis of six cases. J Natl Med Assoc. 1979;71(5):1979. PMID: 2537264.

36. Holm A, Bessey PQ, Aldrete JS. Diaphragmatic rupture due to blunt trauma: morbidity and mortality in 42 cases. South
Med J. 1988;81(8):956-62. PMID: 3406795.

37. Hwang SW, Kim HY, Byun JH. Management of patients with traumatic rupture of the diaphragm. Korean J Thorac Cardiovasc Surg. 2011;44(5):348-54. doi: 10.5090/ kjtcs.2011.44.5.348.

38. Karnak I, Senocak ME, Tanyel FC, Büyükpamukçu N. Diaphragmatic Injuries in childhood. Surg Today. 2001;31(1):5-11. doi: $10.1007 / \mathrm{s} 005950170212$.

39. Kishore GSB, Gupta V, Doley RP, Kudari A, Kalra N, Yadav TD, Wiq JD. Traumatic diaphragmatic hernia: tertiary centre experience. Hernia. 2010;14(2):159-64. doi: 10.1007/s10029-009-0579-x.

40.Lenot B, Bellenot F, Regnard JF, Dartevelle $P$, Rojas-Miranda A, Levasseur P. Les ruptures du diaphragme de révélation tardive. Ann Chir. 1990;44(2):157-60.

41.Lin YK, Huang BS, Shih CS, Hsu WH, Huaug $\mathrm{MH}$, Lee $\mathrm{CH}$. Traumatic diaphragmatic hernia with delayed presentation. Zhonghua Yi Xue Za Zhi (Taipei). 1999;62(4):223-9.

42.Lindseyl, Woods SD, Nottle PD. Laparoscopic management of blunt diaphragmatic injury. Aust N Z J Surg. 1997;67(9):619-21. PMID: 9322698.

43.Losanoff JE, Richman BW, Asparouhova DD, Jones JW. Traumatic disruption of the diaphragm: emergency diagnosis and treatment. Eur Surg. 2005;37(4):254-8. doi: 10.1007/s10353-005-0162-3.

44. Matthews BD, Bui $H$, Harold $K L$, Kercher KW, Adrales G, Park A, Sing RF, Heniford BT. Laparoscopic repair of traumatic diaphragmatic injuries. Surg Endosc. 2003;17(2):254-8. doi: 10.1007/s00464002-8831-9.

45. Mattila S, Järvinen A, Mattila T, Ketonen P. Traumatic diaphragmatic hernia. Report of 50 cases. Acta Chir Scand. 1977;143(5):3138.

46.Matz A, Landau O, Alis M, Charuzi I, Kyzer S. The role of laparoscopy in the diagnosis and treatment of missed diaphragmatic rupture. Surg Endosc. 2000;14(6):537-9. PMID: 10890960.

47. Mihos P, Potaris K, Gakidis J, Paraskevopoulos J, Varvatsoulis P, Gougoutas B, Papadakis $G$, Lapidakis E. Traumatic rupture of the diaphragm: experience with 65 patients. Injury. 2003;34(3):169-72. PMID: 12623245. 
48. Montresor E, Mangiante $G$, Lupi A, Di Guida V, Falezza $G$, Attino $M$, Ragni $E$, Vassia S, Aurola P. Diagnosis and treatment of traumatic diaphragmatic hernia with delayed presentation. Minerva Chir. 1997;52(7-8):919-25. PMID: 9411293.

49.Nadal SR, Duarte Jr E, Nadal CRM, Nadal OS, Speranzini MB. Hernia diafragmática traumática estrangulada. Rev Col Bras Cir. 1992;19(5):199-203.

50.Noon GP, Beall AC, de Bakey ME. Surgical management of traumatic rupture of the diaphragm. J Trauma. 1966;6(3):344-52. PMID: 5934278.

51.Okan I, Baş G, Ziyade S, Alimoğlu O, Eryılmaz R, Güzey D, Zilan A. Delayed presentation of posttraumatic diaphragmatic hernia. Ulus Travma Acil Cerrahi Derg. 2011;17(5):435-9. PMID: 22090330.

52.Okur MH, Uygun I, Arslan MS, Aydogdu B, Turkoglu A, Goya C, Icen M, Cigdem MK, Onen A, Otcu S. Traumatic diaphragmatic rupture in children. J Pediatr Surg. 2014;49(3):4203. doi: 10.1016/j.jpedsurg.2013.11.056.

53.Olin C. Traumatic rupture of the diaphragm. Report of eleven cases. Acta Chir Scand. 1975;141(4):282-4.

54.Pantelis D, Burger C, Hirner A, Wolff $M$. Trauma mechanism and diagnosis of blunt diaphragmatic rupture. Chirurg. 2005;77(4):360-6. doi: 10.1007/s00104005-1103-1.

55.Payne Jr JH, Yellin AE. Traumatic diaphragmatic hernia. Arch Surg. 1982;117(1):18-24. PMID: 7055422.

56.Plate $H$, Demischew M. Neglected traumatic diaphragmatic rupture in a thoracic surgery patient sample. Zentralbl Chir. 1989;114(6):393-6.

57.Ruf G, Mappes HJ, Kohlberger E, Baumgartner $U$, Farthmann EH. Diagnosis and therapy of diaphragmatic rupture after blunt thoracic and abdominal trauma. Zentralbl Chir. 1996;121(1):24-9. PMID: 8852737.

58.Sanli $M$, Isik AF, Tunçözgür $B$, Meteroglu $\mathrm{F}$, Elbeyli L. Diagnosis that should be remembered during evaluation of trauma patients: diaphragmatic rupture. Ulus Travma Acil Cerrahi Derg. 2009;15(1):71-6. PMID: 19130342.
59.Sharma OP. Traumatic diaphragmatic rupture: not an uncommon entity-personal experience with collective review of the 1980's. J Trauma. 1989;29(5):678-82. PMID: 2657086.

60.Simpson J, Lobo DN, Shah AB, Rowlands BJ. Traumatic diaphragmatic rupture: associated injuries and outcome. Ann R Coll Surg Engl. 2000;82(2):97-100. PMID: 1074342.

61.Sözübir S, Tander B, Bernay F, Aritürk E, Rizalar R, Gürses N. Traumatic diaphragmatic rupture in children. Ulus Travma Acil Cerrahi Derg. 2005;11(1):64-8.

62.Sukul DM, Kats E, Johannes EJ. Sixty-three cases of traumatic injury of the diaphragm. Injury. 1991;22(4):303-30. PMID: 1937728.

63.Sutton JP, Carlisle RB, Stephenson Jr SE. Traumatic diaphragmatic hernia a review of 25 cases. Ann Thor Surg. 1967;3(2):136-50. PMID: 4951725.

64.Tan KK, Yan ZY, Vijayan A, Chiu MT. Management of diaphragmatic rupture from blunt trauma. Singapore Med J. 2009;50(12):1150. PMID: 20087550.

65.Tarladaçalışır T, Karamustafaoglu YA, Yörük Y. [Factors affecting mortality in traumatic diaphragmatic ruptures]. Türk Göğüs Kalp Damar Cerrahi Derg. 2014;22(1):118-25. doi: 10.5606/tgkdc.dergisi.2014.8700.

66. Tiberio GAM, Portolani N, Coniglio A, Baiocchi GL, Vettoretto N, Giulini SM. Traumatic lesions of the diaphragm. Our experience in 33 cases and review of the literature. Acta Chir Belg. 2005;105(1):82-8. PMID: 15790209.

67.Turhan K, Makay O, Cakan A, Samancilar $\mathrm{O}$, Firat $\mathrm{O}$, Icoz G, Cagirici U. Traumatic diaphragmatic rupture: look to see. Eur J Cardiothorac Surg. 2008;33(6):1082-5. doi: 10.1016/j.ejcts.2008.01.029.

68.van Vugt AB, Schoots FJ. Acute diaphragmatic rupture due to blunt trauma: a retrospective analysis. J Trauma. 1989;29(5):683-6. PMID: 2724386.

69.Vatansev C, Aksoy F, Tekin S,Tekin A, Belviranli $M$, Kaynak $A$. Diaphragmatic rupture in abdominal trauma. Ulus Travma Derg. 2003;9(4):285-90.

70.Vergnaud JP, Lopera C, Penagos S, Vásquez J. Corrección laparoscópica de hernias 
diafragmáticas traumáticas. Reporte de doce casos. Rev Colomb Cir. 2002;17(3):14650.

71.Yalçinkaya I, Kisli E. Traumatic diaphragmatic rupture: results of the chest surgery clinic. Ulus Travma Acil Cerrahi Derg. 2008;14(3):221-5. PMID: 18781419.

\section{Correspondence:}

Antonio Jose Maria Cataneo

Disciplina de Cirurgia Torácica, Departamento de Cirurgia, UNESP

Avenida Prof. Mario Rubens Guimarães Monte Negro, s/n

18618-687 Botucatu - SP Brasil

Tel.: (55 14)3880-1528

acataneo@fmb.unesp.br

Received: Sep 05, 2017

Review: Nov 06, 2017

Accepted: Dec 09, 2017
Conflict of interest: none

Financial source: none

\begin{abstract}
${ }^{1}$ Research performed at Division of Thoracic Surgery, Department of Surgery, Botucatu School of Medicine, Universidade Estadual Paulista (UNESP), Botucatu-SP, Brazil. Part of Master degree thesis, Postgraduate Program in Medicine. Tutor: Antonio Jose Maria Cataneo.
\end{abstract}

